\title{
An Image-based Gradation Calculation Method Considering Crushed Stone Morphology
}

\author{
Chong Jiang \\ Central South University \\ Xin Ding \\ Central South University \\ Li Pang ( $\nabla$ pangli@csu.edu.cn ) \\ Central South University \\ Liang Deng \\ Central South University \\ Zexiong Shi \\ Central South University
}

\section{Research Article}

Keywords:

Posted Date: June 6th, 2022

DOI: https://doi.org/10.21203/rs.3.rs-1257691/v2

License: (c) (1) This work is licensed under a Creative Commons Attribution 4.0 International License. Read Full License 


\title{
An Image-based Gradation Calculation Method Considering
}

\section{Crushed Stone Morphology}

\author{
Chong jiang ${ }^{1}$, Xin Ding ${ }^{1}$, Li Pang ${ }^{1}{ }^{*}$, Liang Deng ${ }^{1}$, Zexiong Shi ${ }^{1}$ \\ ${ }^{1}$ School of Resources and Safety Engineering, Central South University, Changsha \\ 410083, Hunan, China. *email: pangli@csu.edu.cn
}

An image-based gradation calculation method considering crushed stone morphology is proposed in this paper. Eight kinds of crushed stones are prepared to figure out the effect of the particle shape on the gradation. All particles are pictured and the photos are processed to obtain particle shape indices by using the imagebased method. A minimum Feret diameter analysis method is used, which can reflect the influence of the particle shape. Then the paper proposes a developed overall regularity to describe the morphology of particles, which is calculated by the weight of three shape indices: aspect ratio, convexity and sphericity. The developed overall regularity is applied on gradation curve equations to provide an image-based gradation calculation method. And the provided method is validated to well fit the actual case. Furthermore, the method is also applied on two examples of gradation designation and the result proves to be feasible and practicable.

Crushed stone is small pieces of the broken rock due to natural reasons or man-made destruction, which has irregular size, shape and texture. Materials with different particle size distribution are often used to form coarse aggregate ${ }^{1-3}$, backfill material ${ }^{4-7}$ and rockfill ${ }^{8-10}$ in high fill, subgrade and mining engineering. There are various parameters describing soil materials, among which the particle size and gradation are commonly used. Gradation is known to be defined as the distribution of aggregate particles of different sizes, which can be determined by sieve analysis test. However, the pore of the sieves are generally composed by a lattice square according to the method of British Standards Institute ${ }^{11}$, which sometimes makes particles of quiet different characteristics have the same size ${ }^{12}$. This brings about difficulties to design the gradation for different kinds of materials in engineering.

Particle geometry is a result of the genesis of the parent rock, stages of transportation and depositional history, and chemical and biological effects ${ }^{13}$. For particulate materials including crushed stones, the characteristics of the particle shape govern their complex mechanical behavior at multi-scales, about which the research interest has been growing in recent years ${ }^{14,15}$. Since Wadell ${ }^{16}$ first proposed the shape parameter: sphericity, the parameter evaluating the particle shape has been developed and the number of the parameter has been added. Traditional methods are to make use of charts such as the charts of Krumbein and Sloss ${ }^{17}$ and Cho et al. ${ }^{18}$.The roundness and sphericity of a given particle are assessed by visual comparison with the reference shapes in these charts. Lee et al. ${ }^{15}$ not only redefined sphericity but also selected 
elongation, slenderness, and convexity to describe the irregularity of sand grains. Berrezueta et al. ${ }^{19}$ evaluated the representativity of four independent $2 \mathrm{D}$ particle parameters which included fractal dimension, Wadell's roundness, a perimeter-area normalized ratio and sphericity. Liu et al. ${ }^{20}$ proposed an empirical small-strain shear modulus model including a Fourier-based particle shape factor modified by gradation through a series of shear wave velocity tests.

Recently, with the application of the computer image processing technology, the accuracy of the particle shape measurements has been improved. An image-based method is known to be a relatively convenient and accurate method, which can obtain particle shape data by using image processing software ${ }^{20-32}$. Basically, particles are usually pictured finely or roughly and the photos are processed in specific software such as Image $\mathrm{J}^{20,29,31}$ and OnDemand $3 \mathrm{D}^{32}$ to obtain the particle shape indices. Some researchers used professional instruments to measure the particle shape of sand and reviews the particle shape effect on mechanical behavior such as QICPIC ${ }^{21,22,27}$, Sedimaging $^{24}$ and $\mathrm{CX}^{30}$ systems. Moreover, some computational algorithm was proposed to be integrated into existing optical soil characterization systems ${ }^{25,26}$. The software or apparatus used by these researchers are mainly focus on soil or sand materials. Different from these small particles, the shape measurement of crushed stone is easier and the requirement of apparatus is lower.

The gradation of materials is usually described by non-uniformity coefficient $\left(C_{u}\right)$ and curvature coefficient $\left(C_{c}\right)$, which is determined by effective particle size $\left(D_{10}\right)$, mean particle size $\left(D_{50}\right)$ and controlling particle size $\left(D_{60}\right)$. However, the method cannot fully express the characteristics of the gradation. A gradation curve equation method is proposed by researchers to overcome the shortcomings. Since Fuller and Thompson $^{33}$ and Talbot and Richart ${ }^{34}$ proposed the equations of maximum density gradation curves and fractal gradation curves, respectively, the studies on gradation curve equations have been developed. Zhu et al. ${ }^{35}$ and Guo et al. ${ }^{36}$ proposed a gradation equation mainly focused on soil and coarse-grained soil. Then Wu et al. ${ }^{37}$ improved the method to reduce the required parameters. Zhu et al. ${ }^{38}$ provided a gradation design method for rockfill materials based on fractal theory. Sun et al. ${ }^{39}$ studied the particle generation procedure in DEM and proposed a gradation algorithm based on the particle number. The gradation curve equations are used to design the required gradation and has been gradually applied on the engineering.

To figure out the effect of particle shape when designing the gradation of aggregate, in this paper, eight kinds of crushed stones are prepared. The stones are divided into two groups which are small particle group and large particle group. The gradations for each group are processed to be the same by sieving. Meanwhile, the image processing software are used to obtain shape indices, including the minimum Feret diameter, aspect ratio, convexity and sphericity. The minimum Feret diameter of particles which can reflect the particle shape effect are measured to form gradations. To quantitatively analyze this particle shape effect, a developed overall regularity is proposed, which is calculated by the weight of the aspect ratio, convexity and sphericity. The developed 
83 overall regularity is applied on the gradation curve equations to provide an image-based

84 gradation calculation method. The new proposed gradation calculation method is

85 validated to be well fitted and the method is applied to two examples of gradation

86 designation. The objective and methodology are shown in Table 1.

87

\begin{tabular}{|l|l|}
\hline Opinions & Methodology \\
\hline $\begin{array}{l}\text { The sieve analysis method sometimes makes particles of quiet } \\
\text { different characteristics have the same size. A developed measure } \\
\text { method should be proposed to reflect the particle shape effect. }\end{array}$ & $\begin{array}{l}\text { Eight kinds of crushed stones with different particle shape are sieved } \\
\text { to be the same gradation. Additionally, the minimum Feret diameter } \\
\text { formed by sieve analysis and } D^{\text {Fmin }} \text { analysis are compared to reflect } \\
\text { the particle shape effect on gradation curves. }\end{array}$ \\
\hline $\begin{array}{l}\text { The particle shape of crushed stones can be quantified to be an index, } \\
\text { which can evaluate whether a particle is rounded or angular. }\end{array}$ & $\begin{array}{l}\text { The image processing software are used to obtain shape indices, } \\
\text { including the aspect ratio, convexity and sphericity. Take the weight } \\
\text { of these indices, a developed overall regularity }(O R) \text { is proposed to } \\
\text { quantitatively analyze the particle shape effect. }\end{array}$ \\
\hline $\begin{array}{l}\text { The current gradation curve equation can be developed to consider } \\
\text { the particle shape effect. }\end{array}$ & $\begin{array}{l}\text { A developed continuous gradation equation is proposed. The key } \\
\text { parameters in the equation are related to the developed overall } \\
\text { regularity }(O R) \text { Moreover, to reflect the particle shape diameter, the } \\
\text { traditional diameter of the sieved particle }(D) \text { is replaced by the } \\
\text { minimum Feret diameter }\left(D^{\text {Fmin }) .}\right.\end{array}$ \\
\hline
\end{tabular}

88 Table 1. The opinions and the methodology.

89 Significance of the proposed method

90 In this paper, a gradation calculation method considering the shape of crushed stone

91 based on image analysis is proposed.

92 The proposed method is relatively accurate comparing with the traditional

93 gradation calculation method. Generally, particles are sieved to obtain sizes to form the

94 gradation. However, the sieve hole of the sizing screen is round or square, which may

95 mislead the designation in the engineering because particles with different particle

96 shape can have the same gradation by sieving. To overcome the weakness of the current

97 method, based on the image-based method, a more accurate gradation calculation

98 method is proposed.

99 The proposed method is also practical and effective in the engineering. Comparing

100 with sand, clay and other small size particles, the crushed stone is relatively large in

101 size. It's enough to picture the crushed stone using normal camera instead of using high-

102 precision equipment. By using image processing software, the particle shape indices

103 are easy to be obtained. These make the proposed method applicable on the engineering.

\section{Results}

106 Particle material and gradation. Eight kinds of materials with different particle

107 shapes are involved in the experiment as Fig. 1. Table 2 shows the summary of the

108 geological classification and characteristics, particle shape classification of the

109 materials. 


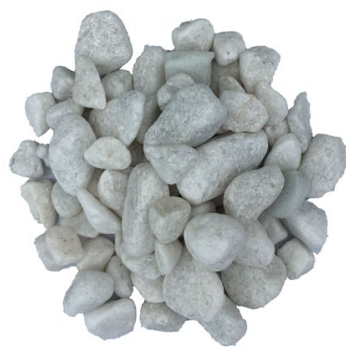

White pebbles

111

112

113

114

115

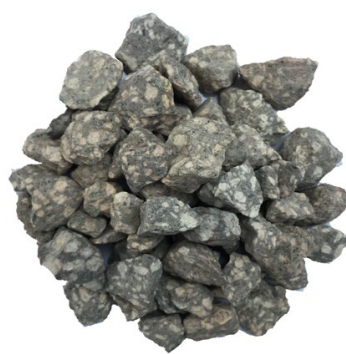

Medical stone

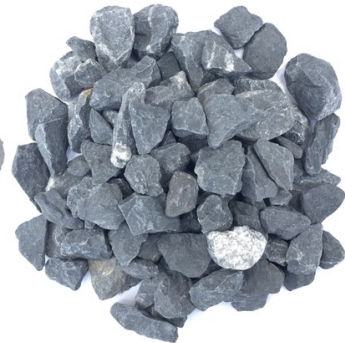

Black stone

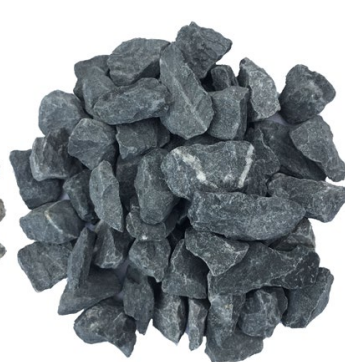

Guangxi stone

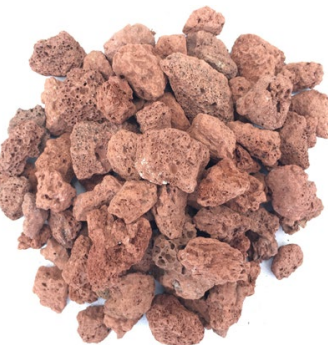

Basalt

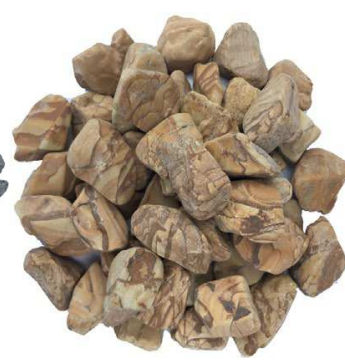

Sepenggiante

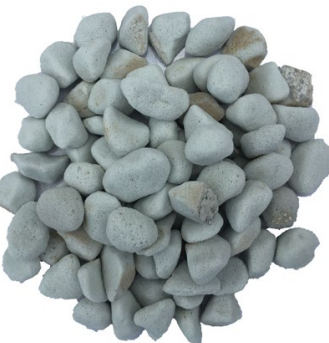

Perlite

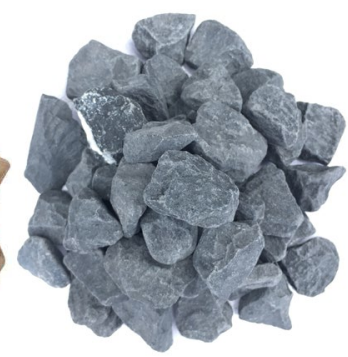

Limestone

Fig. 1. Eight kinds of materials used in the experiment.

\begin{tabular}{|l|l|l|}
\hline Stone & Geological classification and characteristics & Particle shape \\
\hline White pebbles & Nearly pure silica stone with smoother surface & Sub-rounded \\
\hline Black stone & Carbonate stone & Angular \\
\hline Basalt & Porous stone about $40 \%$ void ratio, $45 \%$ silica and $30 \% \mathrm{Fe}_{2} \mathrm{O}_{3}, \mathrm{CaO}$ & Angular \\
\hline Perlite & Fragile vitreous stone composed of $70 \%$ silica and $12 \%$ alumina & Sub-rounded \\
\hline Medical stone & Aluminosilicate stone with dense composition & Sub-angular \\
\hline Guangxi stone & Carbonate stone with quartz grain & Angular \\
\hline Sepenggiante & Hard Marble stone with the grain of tree & Sub-rounded \\
\hline Limestone & Carbonate stone with roughness surface, $\mathrm{CaCO}_{3}$ over $90 \%$ & Sub-angular \\
\hline
\end{tabular}

116 Table 2. Summary of the geological classification and characteristics and particle shape

117 classification.

According to their sizes, the eight kinds of crushed stones are divided into two

120 categories: one includes white pebbles, black stone, basalt, perlite, medical stone with

121 the larger size; the other includes Guangxi stone, sepenggiante, limestone with the

122 smaller size. The particle size distribution curves of the eight crushed stone are

123 controlled by sieving to be exactly the same, giving the mean particle diameter

$124 D_{50}^{\text {sieve }}=15.5 \mathrm{~mm}$ and uniformity coefficient $C_{u}^{\text {sieve }}=1.34$ for smaller particles as

125 the black line in Fig. $2 \mathrm{a} ; D_{50}^{\text {sieve }}=20.5 \mathrm{~mm}$ and uniformity coefficient $C_{u}^{\text {sieve }}=1.15$

126 for larger particles as the black line in Fig. $2 b$. 


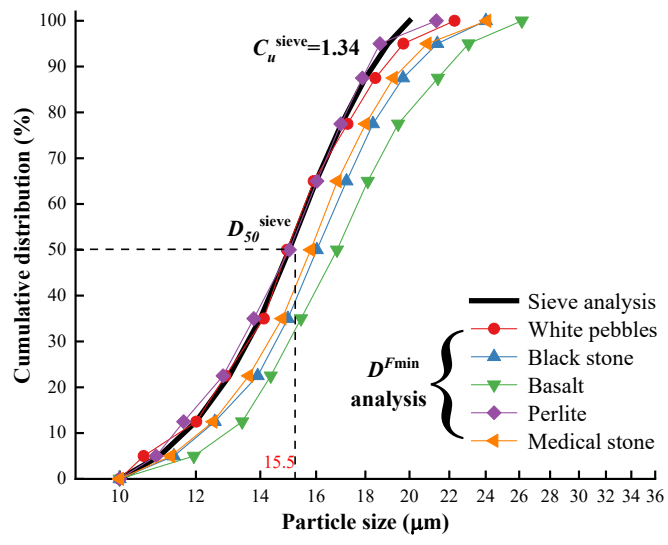

(a)small particles

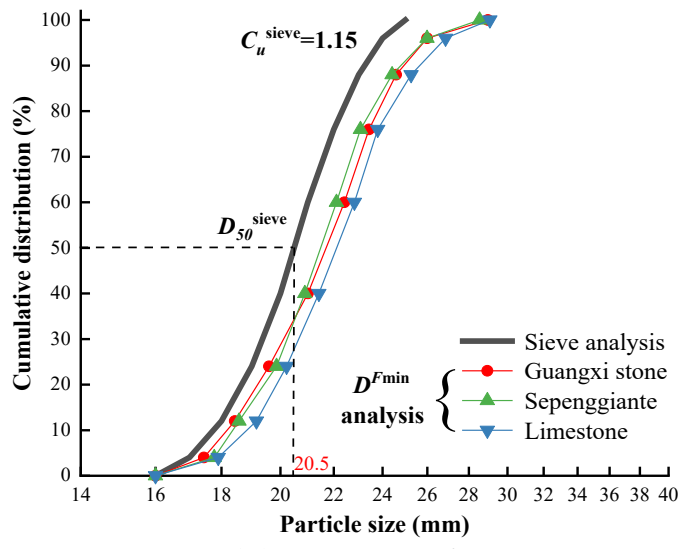

(b)large particles

Fig. 2. Particle size cumulative distribution for sieve analysis and $D^{F m i n}$ analysis.

Besides the conventional sieving results, an imaging-based method is also used to obtain particle size and gradation. Over 2000 particles are pictured to obtain the particle indices, and the number of each kind of stones is the same for a qualitative comparison. Several indices measured by this method can describe the size of the particle, along which the minimum Feret diameter $\left(D^{F \min }\right)$ is used in this paper, and $D^{F m i n}$ means the smallest distance between two tangents on opposite sides of the particle, as shown in Fig. 3a.

Particle shape measurements. Three shape indices are used in this paper and have been widely used in recent years ${ }^{21,22,27,28}$, namely the aspect ratio $(A R)$, the convexity $(C)$ and the sphericity $(S)$, as shown in Fig. 3: $A R$ is defined as the ratio between $D^{F \min }$ and $D^{\text {Fmax }} ; C$ is defined by the ratio between the area of the particle $(A)$ and the area of the convex hull of the particle $(A+B) ; S$ is defined as the ratio between the perimeter of a circle with the same area as the projected area of the particle and its real perimeter.

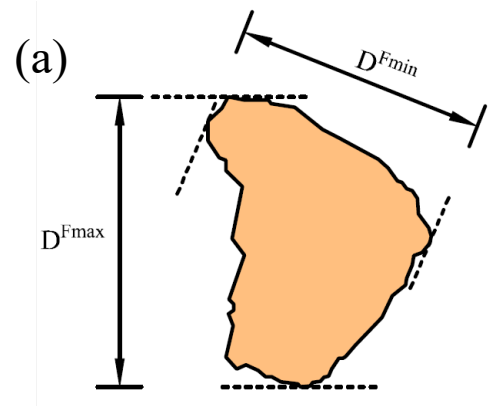

Aspect ratio: $\mathrm{AR}=\mathrm{D}^{\mathrm{Fmin} / \mathrm{D}^{\mathrm{Fmax}}}$ (b)

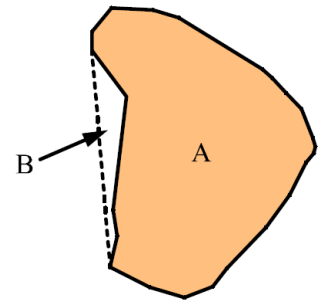

Convexity: $\mathrm{C}=\mathrm{A} /(\mathrm{A}+\mathrm{B})$ (c)

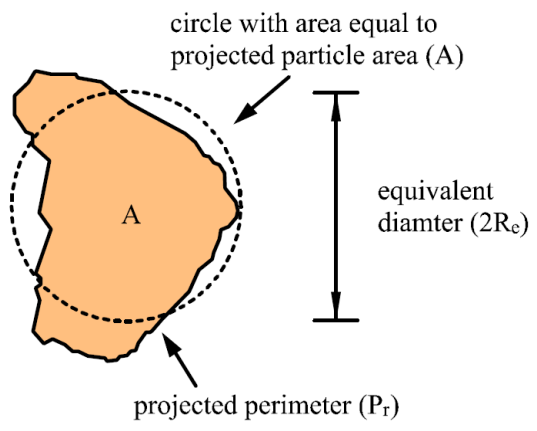

Sphericity: $\mathrm{S}=2 \pi \mathrm{R}_{\mathrm{e}} / \mathrm{P}_{\mathrm{r}}$

Fig.3. Definition of shape and size indices.

Fig. 4 presents the cumulative distribution of shape measurements of eight crushed stones. Different from the results of the glass beads by Yang and $\mathrm{Luo}^{27}$, the range of the 
convexity $(C)$ is normally from 0.9 to 1 for crushed stone, but the range of the aspect 153 ratio $(A R)$ and the sphericity $(S)$ are similar. For a given material, it is reasonable to 154 choose the shape value corresponding to the $50 \%$ cumulative distribution as a 155 representative value ${ }^{27}$. In this method, shape data of the eight crushed stones is provided 156 in Table 3.

157

158

(a)

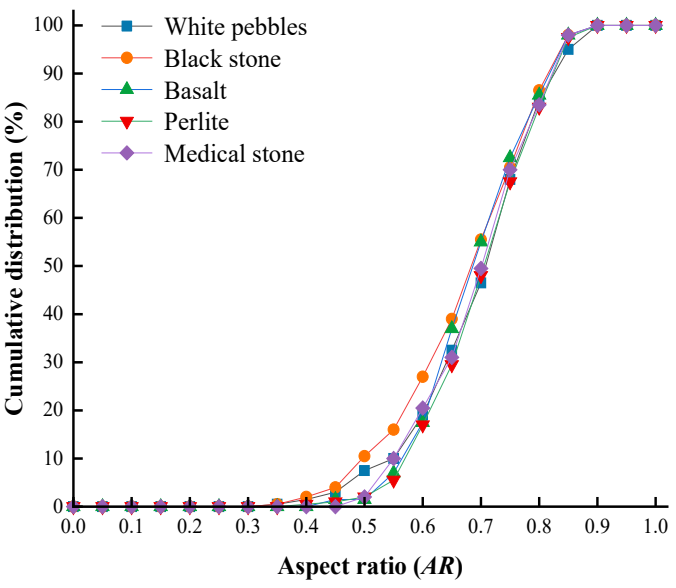

(b)

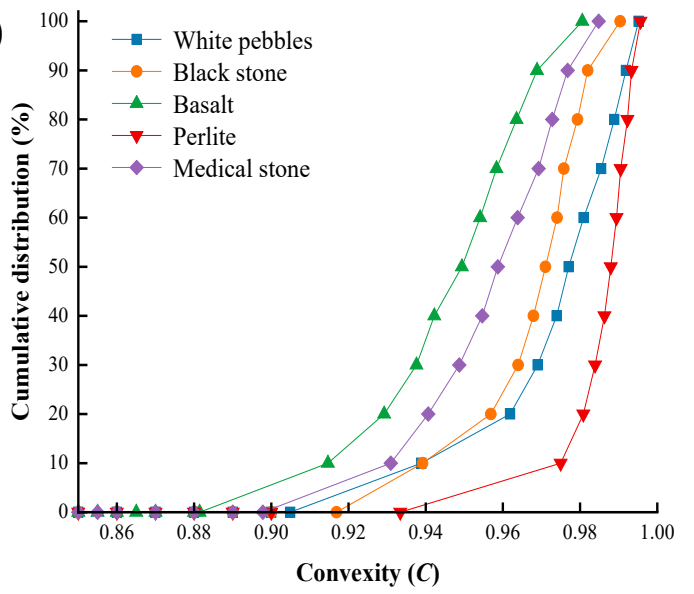

159

(c)

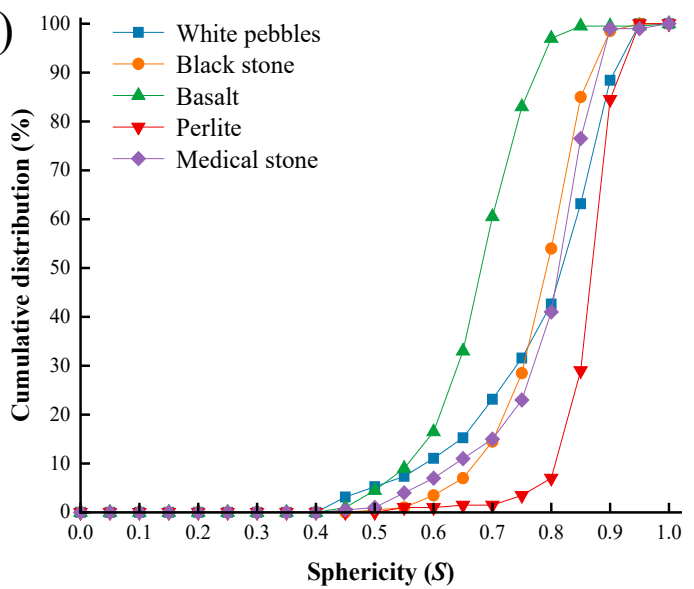

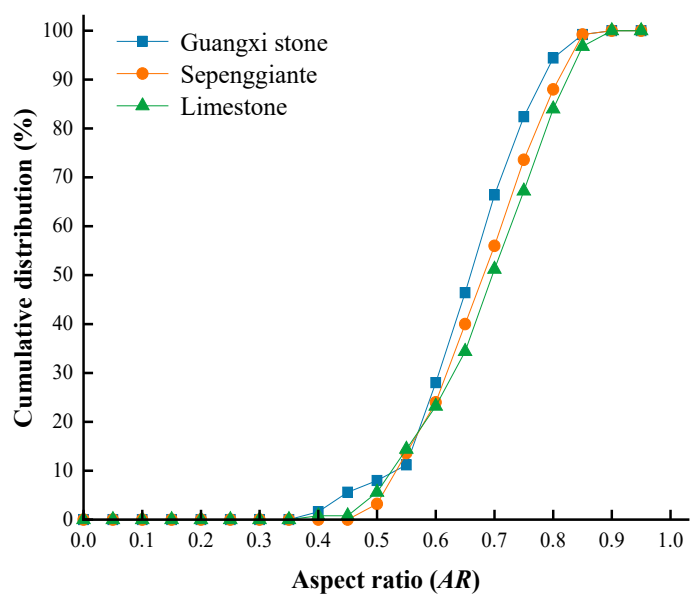
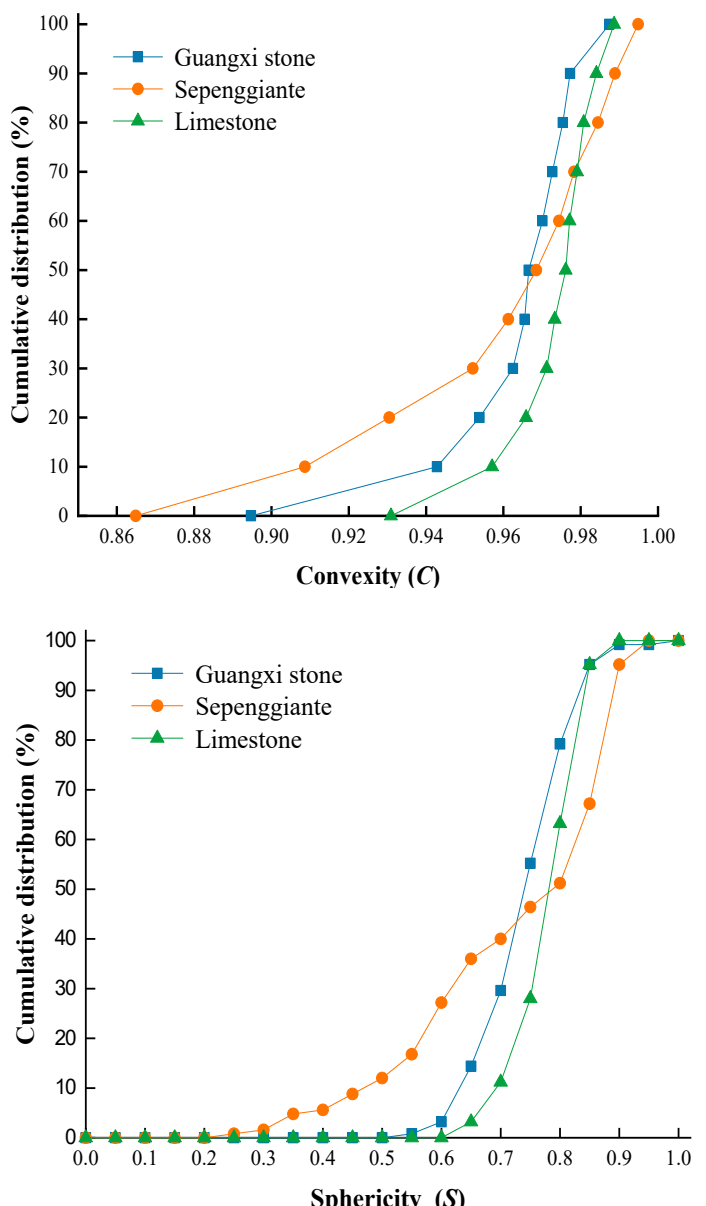

Sphericity $(S)$

161 Fig.4. Cumulative distribution for (a) aspect ratio, (b) convexity and (c) sphericity. 


\begin{tabular}{|c|c|c|c|c|c|}
\hline Material & Aspect ratio $\left(\boldsymbol{A R}_{\mathbf{5 0}}\right)$ & Convexity $\left(\boldsymbol{C}_{\mathbf{5 0}}\right)$ & Sphericity $\left(\boldsymbol{S}_{\mathbf{5 0}}\right)$ & $\boldsymbol{O} \boldsymbol{R}$ of Yang and Luo & $\boldsymbol{O} \boldsymbol{R}$ of present study \\
\hline White pebbles & 0.708 & 0.977 & 0.842 & 0.842 & 0.648 \\
\hline Black stone & 0.683 & 0.971 & 0.792 & 0.815 & 0.562 \\
\hline Basalt & 0.686 & 0.949 & 0.681 & 0.772 & 0.367 \\
\hline Perlite & 0.701 & 0.988 & 0.869 & 0.853 & 0.720 \\
\hline Medical stone & 0.700 & 0.958 & 0.813 & 0.824 & 0.523 \\
\hline Guangxi stone & 0.659 & 0.967 & 0.740 & 0.789 & 0.486 \\
\hline Sepenggiante & 0.681 & 0.968 & 0.788 & 0.812 & 0.543 \\
\hline Limestone & 0.696 & 0.976 & 0.781 & 0.818 & 0.588 \\
\hline
\end{tabular}

164 Table 3. The $50 \%$ cumulative distribution data of the eight materials.

165

166

As shown in Fig. 5, there is a relatively fixed range for each shape indices of aspect

167 ratio, convexity and sphericity, but not distributes in the range of $0 \sim 1$. This means to

168 reflect the real weight of these shape indices, the range needs to be processed. Yang and

$169 \mathrm{Luo}^{27}$ provided a calculation method to describe the morphology of particles, referred

170 to as overall regularity $(O R)$, and can be calculated as the average of the value of three

171 shape indices $\left(A R_{50}+S_{50}+C_{50}\right) / 3$. This means the weights of the three particle

172 shape indices are equal. However, as for crushed stone in this paper, the value of $O R$

173 will reflect more characteristics of $S$ and $C$ in this method, because there are

174 narrower range and larger value for $S$ and $C$ than $A R$. To better reflect the weight of

175 each index, the calculation of the overall regularity $(O R)$ is modified as the following

176 equation:

$$
O R=\left(\frac{A R_{50}-A R_{\min }}{A R_{\max }-A R_{\min }}+\frac{C_{50}-C_{\min }}{C_{\max }-C_{\min }}+\frac{S_{50}-S_{\min }}{S_{\max }-S_{\min }}\right) / 3
$$

178 where the subscript "max" and "min" means the upper and lower bound of the $95 \%$

179 confidence interval, respectively, as shown in Fig. 5. The figure shows the counting

180 number distribution for the three shape indices. It is obvious that the contribution of

181 each particle shape index is concentrated in a certain range. Eq. (1) makes the weights

182 of the three indices the same through the normalization method. Thus, OR with Eq. (1)

183 can describe the particle shape in a collective manner.

184

(a)

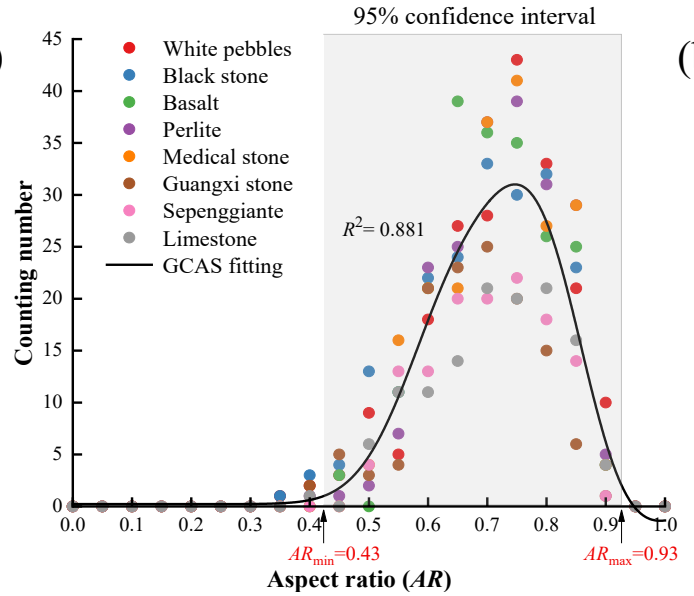

(b)

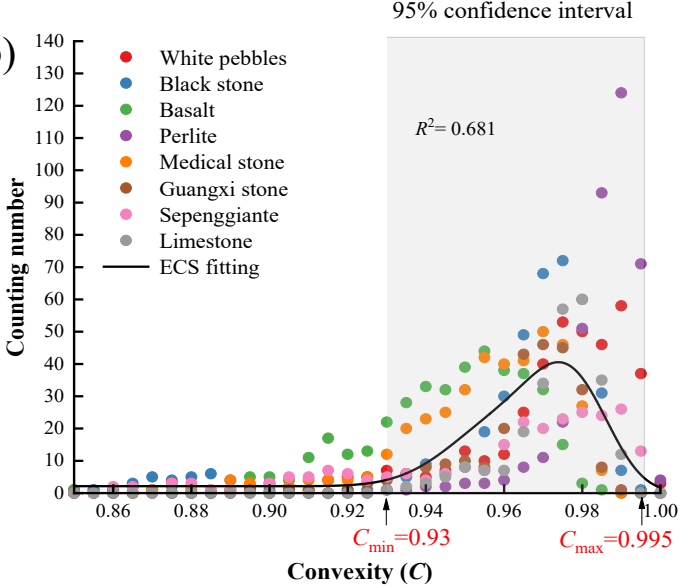


(c)



Fig.5. Counting number distribution for (a) aspect ratio, (b) convexity and (c) sphericity.

Gradation equations. Traditional calculation of particle gradation needs to draw an initial gradation curve first, and interpolate to get the value of effective particle size $\left(D_{10}\right)$ and controlling particle size $\left(D_{60}\right)$. Then calculate uniformity coefficient $\left(C_{u}\right)$ and curvature coefficient $\left(C_{c}\right)$ to check whether the result meets the engineering requirements, and adjusting the initial curve continuously until it finally meets. Comparing the complicated process shown above, the calculation process can be simplified by using the gradation equation method.

The continuous gradation equation proposed by Zhu et al. ${ }^{35}$ and Guo et al. ${ }^{41}$ is used in this paper:

$$
P=\frac{1}{(1-b)\left(D_{\max } / D\right)^{a}+b} \times 100 \%
$$

where $D$ is any particle size within the gradation range; $P$ is the percentage of particles smaller than $D ; D_{\max }$ is the maximum particle size; $a$ and $b$ are dimensionless parameters need to be determined. For minimum Feret diameter $\left(D^{F m i n}\right)$ analysis, Eq. (2) can be expressed as following:

$$
P=\frac{1}{\left(1-b^{F \min }\right)\left(D_{\max }^{\text {Fmin }} / D^{F \min }\right)^{a^{F \min }}+b^{\text {Fmin }}} \times 100 \%
$$

where the superscript "Fmin" means the parameter is obtained by minimum Feret diameter analysis, and the superscript "sieve" used in the following part means the parameter is obtained by sieve analysis.

Zhu et al. ${ }^{35}$ indicated that the gradation curve shape was like ' $\mathrm{S}$ ' for a higher value of $b$. Because the shapes of the gradation curves in Fig. 2 are all like ' $\mathrm{S}$ ', $b=b^{\text {Fmin }}=$ 0.95 is considered to be reasonable. Fitting $D^{F m i n}$ curves with Eq. (3), the values of $a^{\text {Fmin }}$ for each kind of particles are as shown in Table 4. And fitting sieve curves with Eq. (2), the values of $a^{\text {sieve }}$ for sieve analysis of small and large particles are calculated to be 10.37 and 15.28 , respectively. The ratios between $a^{\text {Fmin }}$ and $a^{\text {sieve }}$ are also shown in Table 4. Fig. 6 shows the relationship between overall regularity $(O R)$ and parameter $a^{F m i n} / a^{\text {sieve }}$. A linear equation is provided as following:

$$
a^{\text {Fmin }} / a^{\text {sieve }}=0.40 R+0.5
$$




\begin{tabular}{|l|c|c|c|c|}
\hline Gradation curves & $\boldsymbol{a}^{\text {Fmin }}$ & $\boldsymbol{a}^{\text {Fmin }} / \boldsymbol{a}^{\text {sieve }}$ & $\boldsymbol{D}_{\boldsymbol{m a x}}^{\text {Fmin }}(\mathbf{m m})$ & $\boldsymbol{D}_{\boldsymbol{m} \boldsymbol{m a x}}^{\text {Fmin }} / \boldsymbol{D}_{\boldsymbol{m} \boldsymbol{a x}}^{\text {sieve }}$ \\
\hline White pebbles & 7.735 & 0.746 & 22.282 & 1.114 \\
\hline Black stone & 7.589 & 0.732 & 24.015 & 1.201 \\
\hline Basalt & 6.912 & 0.667 & 26.169 & 1.308 \\
\hline Perlite & 8.438 & 0.814 & 21.330 & 1.066 \\
\hline Medical stone & 7.268 & 0.701 & 24.071 & 1.203 \\
\hline Guangxi stone & 10.52 & 0.688 & 29.970 & 1.199 \\
\hline Sepenggiante & 10.94 & 0.716 & 29.541 & 1.182 \\
\hline Limestone & 11.24 & 0.736 & 29.071 & 1.163 \\
\hline
\end{tabular}

Table 4. The values of $a^{\text {Fmin }}$ and $D^{\text {Fmin }}$ for each kind of gradation curves.

It is obvious that a certain range of $O R$ can be found for particles with different particle shapes in Fig. 6. In the engineering, particle shape indices are needed to calculate $O R$, sometimes making the work relatively complex and inconvenient. Thus, the paper provides a approach to obtain the value of $O R$ as shown in Fig. 6: nearly spherical particles are classified as 'rounded' and $O R=0.8 \sim 0.9$; elliptical or wellshaped particles are classified as 'sub-rounded' and $O R=0.6 \sim 0.8$; particles with some edges and corners are classified as 'sub-angular' and $O R=0.4 \sim 0.6$; crushed and irregular particles are classified as 'angular' and $O R=0.3 \sim 0.4$.

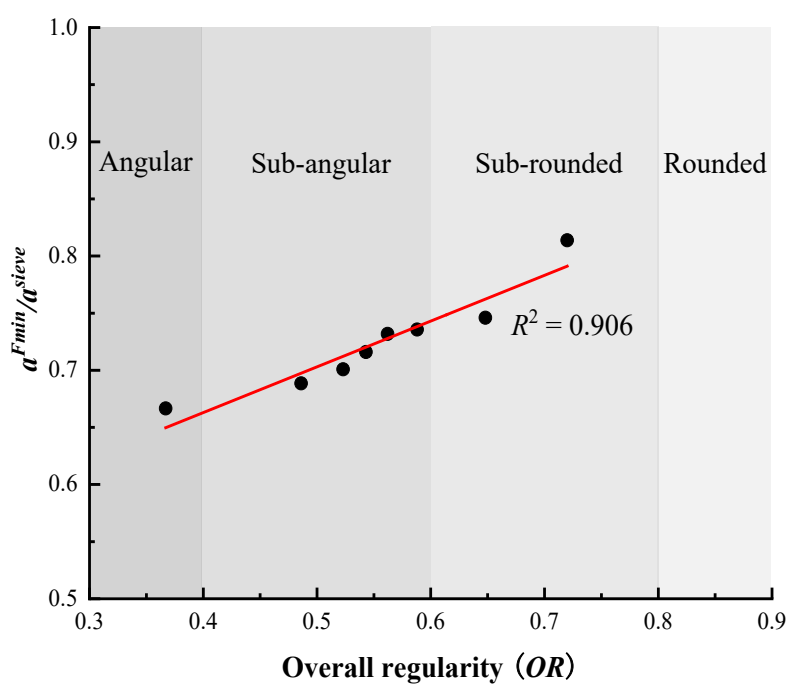

Fig. 6. Curve fitting for overall regularity $(O R)$ versus $a^{F m i n} / a^{\text {sieve }}$.

The value of $D_{\max }^{F \min }$ is also related to $O R$, as shown in Fig. 7. The figure shows that more angular particles have larger $D_{\max }^{F \min }$ comparing to rounded particles. It is noted that the $D^{F m i n}$ size of most rounded particles is exactly the same as the sieve pore size, referred to $D_{\max }^{F \min }=D_{\max }^{\text {sieve }}$. Then an asymptotic relationship is more suitable between $D_{\max }^{F \min } / D_{\max }^{\text {sieve }}$ and $O R$. The equation can be expressed as following:

$$
D_{\max }^{F \min } / D_{\max }^{\text {sieve }}=e^{-3 O R}+1
$$




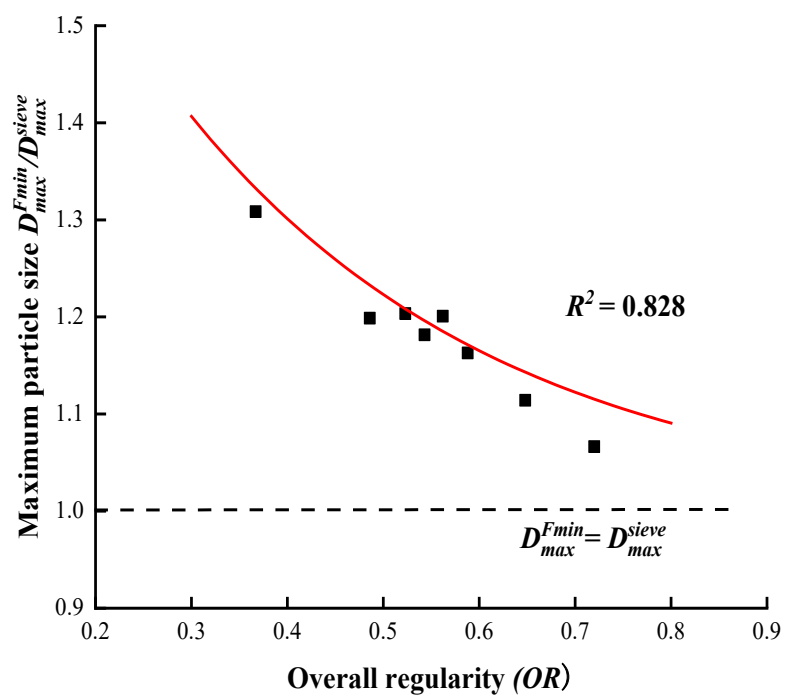

Fig. 7. Curve fitting for overall regularity $(O R)$ versus $D_{\max }^{F \min } / D_{\max }^{\text {sieve }}$.

Then combining Eq. (3) with Eq. (4) and Eq. (5), the following equation can be provided to calculate the gradation considering the effect of particle morphology:

$$
P=\frac{1}{\left(1-b^{F \min }\right)\left[\left(e^{-3 O R}+1\right) D_{\max }^{\text {sieve }} / D^{F \min }\right]^{(0.4 O R+0.5) a^{\text {sieve }}}+b^{\text {Fmin }}} \times 100 \%
$$

The validation of the method. The image-based apparatus, known as QICPIC, have been widely used in recently years to characterize soil particle shape $\mathrm{e}^{14,21,22,27}$. The detailed description of how the apparatus works can be found in Sympatec ${ }^{42}$. Three kinds of particles with different shape are used to figure out the influence of the particle shape on gradation by Yang and $\mathrm{LuO}^{27}$ : glass beads (well-rounded), Fujian sand (subangular) and crushed glass beads (angular). As shown in Fig. 8, the particles are sieved as the same gradation with $C_{u}=1.20$ and $D_{50}=512.5 \mu \mathrm{m}$, together with gradations by $D^{F m i n}$ analysis with apparatus QICPIC. Using the method of Eq. (2), for $b=0.95$, the gradation curve of sieve analysis is fitted and the result proves to be $a^{\text {sieve }}=9.450$.

251 The ranges of the aspect ratio $(A R)$, the convexity $(C)$ and the sphericity $(S)$ are $2520.6 \sim 0.1,0.9 \sim 0.1$ and $0.6 \sim 0.1$, respectively. The $50 \%$ cumulative distribution of 253 the shape indices provided by Yang and $\mathrm{Luo}^{27}$ and the values of the calculated $O R$ with 254 Eq. (1) are shown in Table 5. The maximum sieve diameter $\left(D_{\text {max }}^{\text {sieve }}\right)$ is $700 \mu m$, then 255 the $D^{\text {Fmin }}$ gradation curves can be drawn with Eq. (6) in Fig. 8, which are well fitted with the results provided by the test of Yang and $\mathrm{Luo}^{27}$.

\begin{tabular}{|l|l|l|l|l|}
\hline Material kinds & Aspect ratio $\left(\boldsymbol{A R}_{\mathbf{5 0}}\right)$ & Convexity $\left(\boldsymbol{C}_{\mathbf{5 0}}\right)$ & Sphericity $\left(\boldsymbol{S}_{\mathbf{5 0}}\right)$ & overall regularity $(\boldsymbol{O R})$ \\
\hline Glass beads & 0.974 & 0.974 & 0.944 & 0.845 \\
\hline Fujian sand & 0.745 & 0.956 & 0.891 & 0.550 \\
\hline Crushed glass beads & 0.653 & 0.929 & 0.822 & 0.324 \\
\hline
\end{tabular}

258 Table 5. Shape indices and calculated $O R$. 
It is noted that Eqs. (2) and (3) focuses on the continuous gradation with ' $\mathrm{S}$ ' shape when $b$ approaches 1 . For a smaller value of $b$, the gradation curve shape proves to be hyperbolic, and Eqs. (2) and (3) are still applicable. However, further researches is needed when the curve shape is not continuous, and some researchers have been studied the related contents ${ }^{40,43}$.

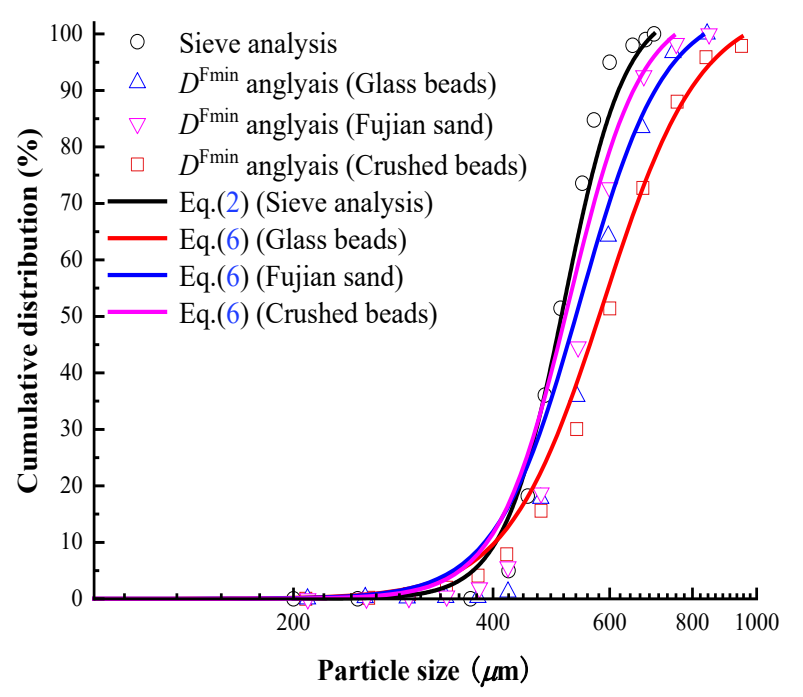

Fig. 8. Validation for three different particles.

Application of the method. Usually, there are two cases to calculate the particle $D_{50}, C_{u}, C_{c}$ ) have been determined and a specific gradation needs to be designed; (2) A particle parameter is fixed and other parameters are changed in a certain interval, and a series of gradations need to be designed. The non-uniformity coefficient $\left(C_{u}\right)$ and the curvature coefficient $\left(C_{c}\right)$ are defined by the following equation:

$$
\begin{gathered}
C_{u}=D_{60} / D_{10} \\
C_{u}=D_{30}{ }^{2} /\left(D_{10} D_{60}\right)
\end{gathered}
$$

where $D_{10}, D_{30}$ and $D_{60}$ are the particle sizes of $10 \%, 30 \%$ and $60 \%$ by weight, repectively. The calculation method by using the new image-based gradation calculation method is shown in detail in the following sub-sections.

An example of three different kinds of particle shapes of sands is used to design gradation curves by Ren et al. ${ }^{44}$. Calcareous sand, standard sand and glass beads are used and can be classified as 'angular', 'sub-angular' and 'rounded'. The parameters $C_{u}=8$ and 10 and $C_{c}=1.5$ are needed and $D_{\text {max }}^{\text {sieve }}=8 \mathrm{~mm}$. Based on Eq. (2), for $C_{u}=8$ and $C_{c}=1.5$, the following equations can be provided as:

$$
\left\{\begin{array}{c}
C_{u}=\frac{D_{60}}{D_{10}}=\left[\frac{6(1-0.1 b)}{1-0.6 b}\right]^{1 / a^{\text {sieve }}}=8 \\
C_{c}=\frac{D_{30}{ }^{2}}{D_{10} D_{60}}=\left[\frac{3(1-0.1 b)(1-0.6 b)}{2(1-0.3 b)^{2}}\right]^{1 / a^{\text {sieve }}}=1.5
\end{array}\right.
$$

The result of Eq. (9) is $a^{\text {sieve }}=0.241$ and $b=0.925$. Then using the same method, $a^{\text {sieve }}=0.237$ and $b=0.870$ for the case of $C_{u}=10$ and $C_{c}=1.5$. 
Taking the median value of the gradation range of 'angular', 'sub-angular' and 288 'rounded', $O R$ is assumed to be $0.35,0.5$ and 0.85 , respectively. By the method of Eq. (6), the calculation results are shown in Fig. 9. Then using methods to measure $D^{\text {Fmin }}$ for these particles to form the drawn $D^{F m i n}$ gradation curve. At that time, these particles are composed of the required gradation considering the effect of particle shape. This process is the same as Fig. 12.

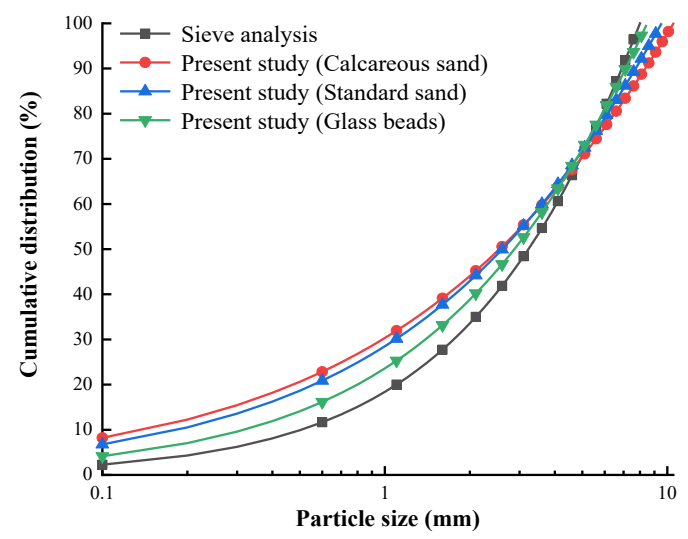

(a) $C_{u}=8$

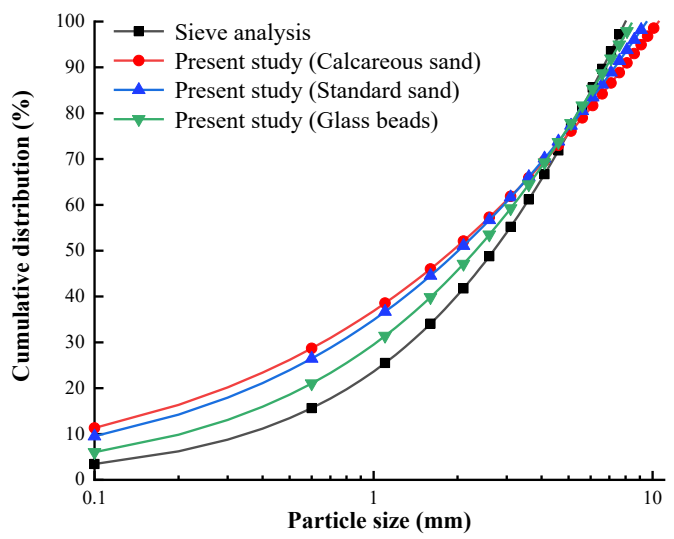

(b) $C_{u}=10$

295 Fig.9. Calculation of a case of the specific gradation.

An example of coarse-grained soil to study the permeability by Peng ${ }^{45}$. The $D_{\text {max }}^{\text {sieve }}=20 \mathrm{~mm}$ for the aggregate of the coarse-grained. The percentage of particles smaller than $10 \mathrm{~mm}$ needs to be $55 \% \sim 75 \%$. Then the non-uniformity coefficient $C_{u}=2.2$ and a series of changing $C_{c}$ is required. Based on Eq. (2), the following

301 equations can be provided as:

$$
\left\{\begin{array}{l}
55 \%<\frac{1}{(1-b)\left(\frac{\text { sieve }_{\text {max }}}{10}\right)^{a^{\text {sieve }}}+b}<75 \% \\
C_{u}=\frac{D_{60}}{D_{10}}=\left[\frac{6(1-0.1 b)}{1-0.6 b}\right]^{1 / a^{\text {sieve }}}=2.2
\end{array}\right.
$$

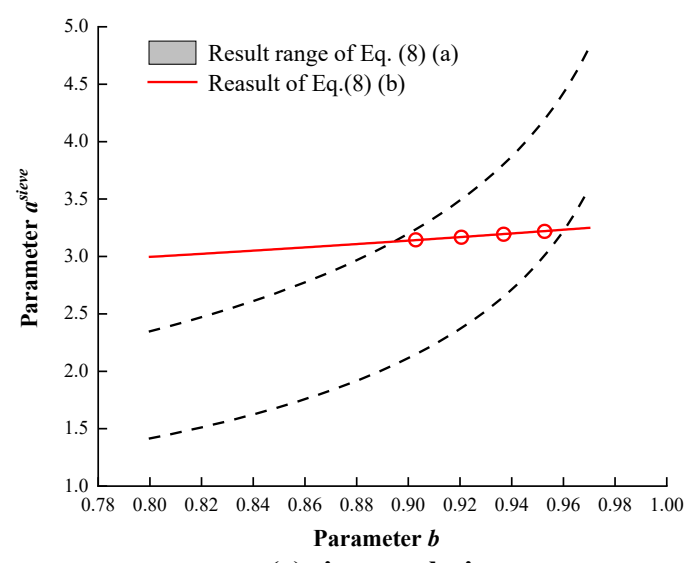

(a) sieve analysis

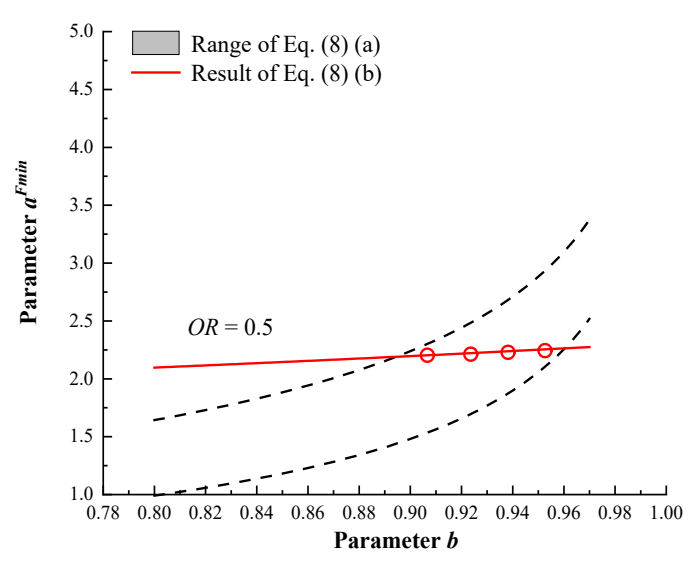

(b)Present study

Fig. 10. Calculation of a case of a series of gradations. 
The sieve analysis result of Eq. (10) is plotted on the plane of $b-a^{\text {sieve }}$, as shown in Fig. 10a. Because the used particles can be classified as 'sub-regular', $O R=0.5$ is assumed in this paper. Then calculating $D_{\max }^{F \min }$ to be $24.46 \mathrm{~mm}$ with Eq. (5) and replacing $a^{\text {sieve }}$ with $\left[a^{F m i n} /(0.4 O R+0.5)\right]$, the $D^{F m i n}$ analysis result of Eq. (10) is plotted on the plane of $b-a^{F m i n}$, as shown in Fig. 10b. Four points are chosen for each analysis of $b=0.9,0.92,0.94$ and 0.96 as the red circle in the figure, then required $C_{c}$ is calculated in Eq. (6) to be 1.054, 1.049, 1.044, 1.040 and 0.738, 0.734, $0.731,0.728$ for sieve analysis and $D^{F m i n}$ analysis, respectively.

\section{Discussion}

The pictures of the eight kinds of crushed stone particles are processed to obtain the particle shape indices. As shown in Fig. 2, the gradation determined by the minimum Feret diameter analysis proves to be different from which is determined by sieve analysis. The gradation curve provided by $D^{F m i n}$ as the size index has been found to be close to but different from that determined by sieve analysis ${ }^{21}$, and the influence of the particle shape can be reflected with the $D^{F m i n}$ analysis ${ }^{27}$. Comparing with the sieve gradation, the minimum Feret diameter gradation can reflect the effect of the particle morphology. The difference between the two gradation curves is relatively small for rounded particles. Conversely, it is large for angular particles. Additionally, Table 6 shows more details about the size distribution curves.

\begin{tabular}{|l|l|l|l|l|l|}
\hline Material & $\boldsymbol{D}_{\mathbf{1 0}}^{\text {Fmin }}(\mathbf{m m})^{\mathbf{a}}$ & $\boldsymbol{D}_{\mathbf{5 0}}^{\text {Fmin }}(\mathbf{m m})^{\mathbf{b}}$ & $\boldsymbol{D}_{\mathbf{6 0}}^{\text {Fmin }}(\mathbf{m m})^{\mathbf{c}}$ & $\boldsymbol{C}_{\boldsymbol{u}}^{\text {Fmind }}$ & $\boldsymbol{C}_{\boldsymbol{u}}^{\text {Sieve }}$ \\
\hline White pebbles & 11.5 & 14.9 & 15.6 & 1.35 & 1.34 \\
\hline Black stone & 12.2 & 16.0 & 16.8 & 1.37 & 1.34 \\
\hline Basalt & 12.9 & 16.8 & 17.7 & 1.37 & 1.34 \\
\hline Perlite & 11.4 & 15.0 & 15.6 & 1.38 & 1.34 \\
\hline Medical stone & 12.1 & 15.8 & 16.3 & 1.35 & 1.34 \\
\hline Guangxi stone & 18.1 & 21.6 & 22.4 & 1.24 & 1.15 \\
\hline Sepenggiante & 18.3 & 21.4 & 22.1 & 1.21 & 1.15 \\
\hline Limestone & 18.7 & 22.1 & 22.8 & 1.22 & 1.15 \\
\hline
\end{tabular}

Table 6. The shape data of the eight materials for the minimum Feret $\left(D^{\text {Fmin }}\right)$ analysis. ${ }^{\mathrm{a}} D_{10}$ is the particle size of the $10 \%$ size distribution curve. ${ }^{\mathrm{b}} D_{50}$ is the mean particle size. ${ }^{\mathrm{c}} D_{60}$ is the particle size of the $60 \%$ size distribution curve. ${ }^{\mathrm{d}} C_{u}$ is the uniformity coefficient defined by $D_{60} / D_{10}$.

Fig. 11 shows the overall regularity $(O R)$ calculation results of Eq. (1) and the method of Yang and $\mathrm{Luo}^{27}$. The difference is obvious for the rather different kinds of particles by using the method of the present study, comparing with the method of Yang and $\mathrm{Luo}^{27}$. The calculation results of Yang and $\mathrm{Luo}^{27}$ for the used particles all concentrate at 0.8 . By using the present method, the range of $O R$ are from 0.3 to 0.8 . For example, $O R=0.367$ for basalt which is irregular and porous, and $O R=0.720$ for perlite which is sub-rounded and smooth. This proves that for different kinds of 
particles, the proposed developed method can distinguish the morphology of them more obviously.

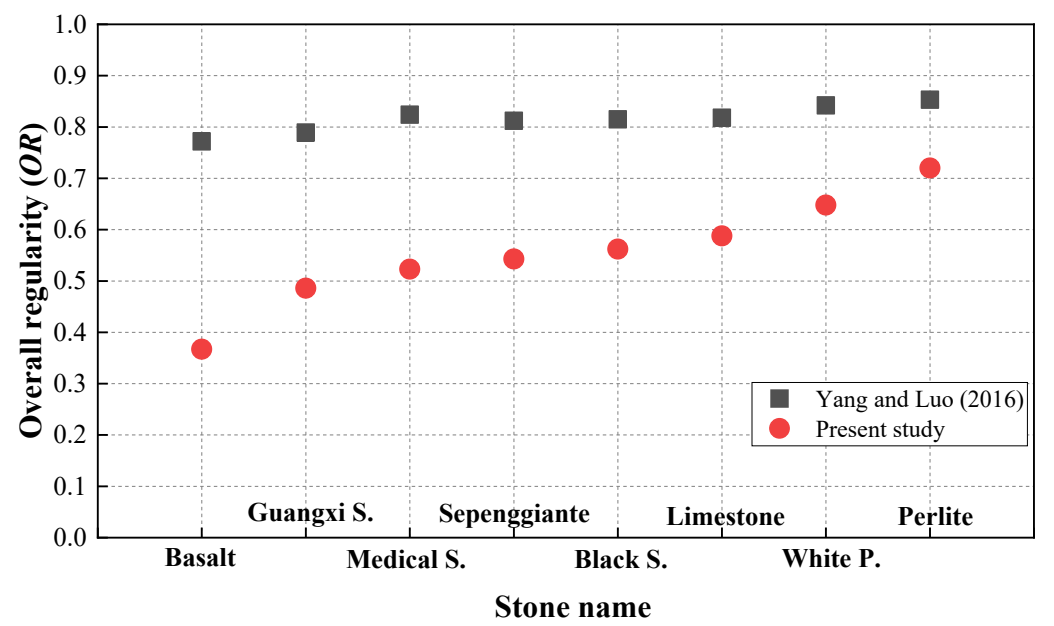

Fig. 11. The results of the method of Yang and $\mathrm{Luo}^{27}$ and the present study.

Fig. 12 shows the process of obtain gradations considering the effect of the particle shape. In the engineering, some parameters are required to design or calculate the gradation: uniformity coefficient $\left(C_{u}\right)$, curvature coefficient $\left(C_{c}\right)$, effective particle size $\left(D_{10}\right)$, mean particle size $D_{50}$, controlling particle size $D_{60}$ or the maximum particle size $D_{\max }$. These parameters are enough to determine a certain gradation curve or a serials of gradation curves. Then with Eq. (2), $a^{\text {sieve }}$ and $b^{\text {sieve }}$ can be obtained. The overall regularity $(O R)$ can be assumed or be calculated more precisely with Eq. (1). Because $D_{\text {max }}^{\text {sieve }}$ is usually provided first, the gradation curve of $D^{F m i n}$ analysis can be drawn in $D^{F m i n}-P$ plane with Eq. (6). The above steps can be accomplished in paper. Then using methods to measure $D^{F m i n}$ for these particles to form the drawn $D^{F m i n}$ gradation curve. At that time, these particles are composed of the required gradation considering the effect of particle shape.

The key part of the proposed method is to obtain $D^{F m i n}$ of the particles. However, different from the sieve analysis, measuring the minimum Feret diameter $D^{F m i n}$ is relatively more difficult. If there are few particles, a calipers can be used to simply measure $D^{F m i n}$. At present, there is no convenient way to obtain $D^{F m i n}$ for a lot of particles. It's time-consuming to measure $D^{\text {Fmin }}$ one by one by using calipers. The image-based method is a relatively practicable approach. Some apparatus are used to measure particle shape parameters in laboratory tests ${ }^{14}$. Moreover, after the particles are pictured by a clear enough camera, the image processing software and numerical calculation software can also be used to obtain the shape parameters. Further studies and more apparatus need to be discussed and developed in the future.

Some problems should also be further studied. The image-based method in this paper is focused on 2D, which is a relatively effective method. The 3D methods have been developed in these years ${ }^{47}$, which is a potential method in the future. 


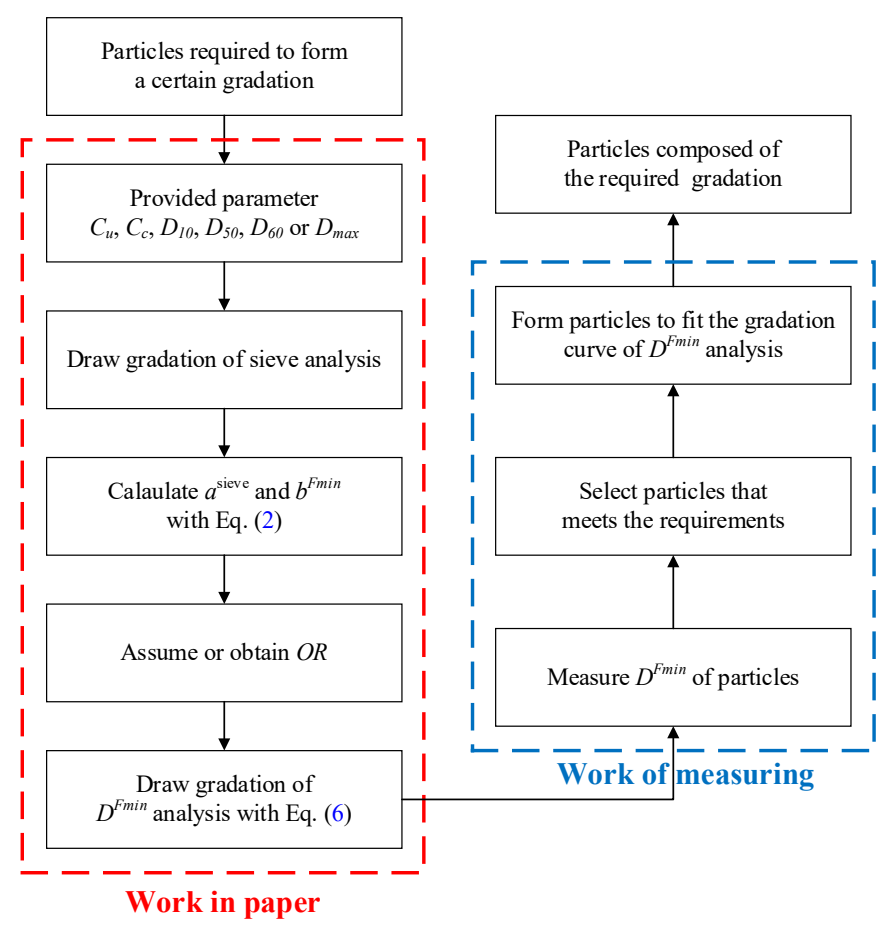

371 Fig. 12. Process of obtain gradations considering the effect of the particle shape.

\section{Methods}

374 Sieve experiment. The eight kinds of crushed stone used in this study have been sieved. The circular sieve aperture diameter is $10 \mathrm{~mm}$ to $30 \mathrm{~mm}$ with $1 \mathrm{~mm}$ interval. To obtain representative and repeatable data for each material, about $5 \mathrm{~kg}$ for each kind of crushed stone with hundreds of particles are used to establish cumulative distribution curves. The sieve mesh and crushed stones of different sizes sieved is shown as Fig. 13.

(a)

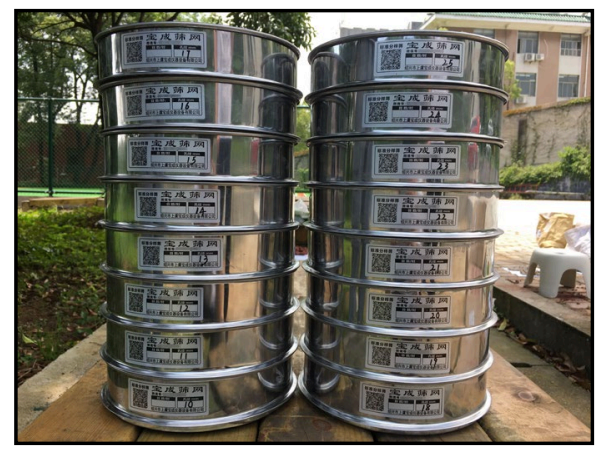

(b)

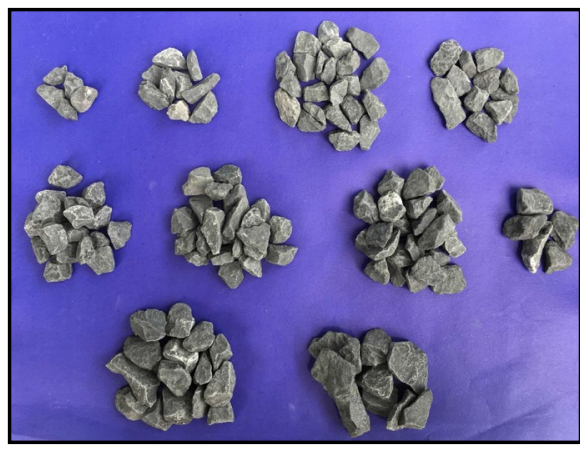

Fig. 13. Sieve experiment. (a) sieve mesh; (b) sieved stone.

Morphological method. The morphology of the crushed stone can be roughly divided into four kinds: 'rounded', 'sub-rounded', 'sub-angular' and 'angular'. However, to quantify the morphology of the particles, many particle shape indices are introduced such as 'aspect ratio', 'convexity', 'sphericity', 'elongation', 'slenderness' and so on. 
the morphology of a particle as Fig. 3, in which the 'aspect ratio' determines whether the shape is close to the normal shape, 'convexity' measures the compactness of a particle and 'sphericity' quantifies the degree of similarity between a particle and a sphere. Then an index $O R$ which is calculated by the weight of the $A R, C$ and $S$ is used to conveniently describe the overall regularity of a particle.

(a)



(c)

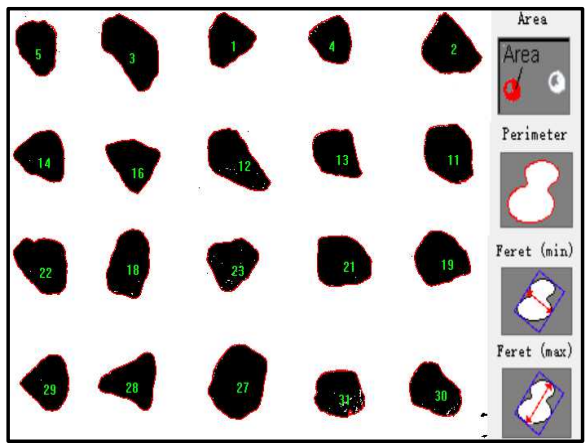

(b)

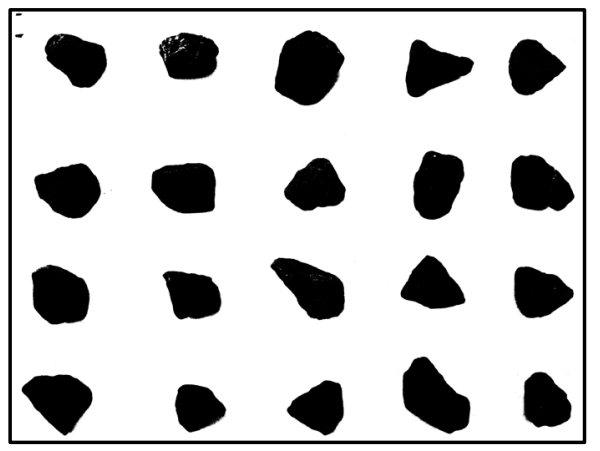

(d)

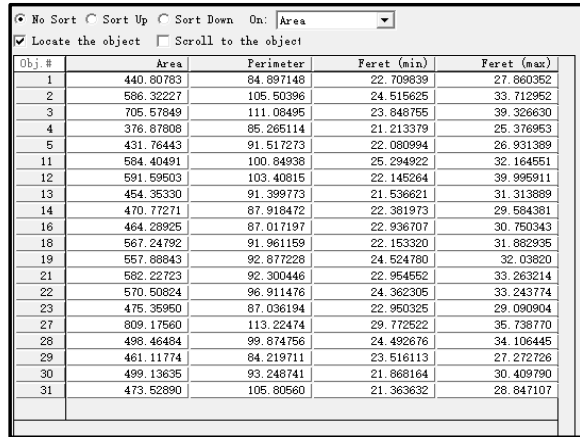

Fig. 14. The image processing procedure to obtain the data of shape indices, which includes (a) taking picture to get real image of the particle, then (b) converting the real image into the binary image, then (c) measuring the shape indices in software, finally (d) obtaining the data of the shape indices.

Image-based method. All particles in the experiment are pictured by camera. Because the particle sizes are around $20 \mathrm{~mm}$, a camera with normal configuration (80 mega pixels) is adequate to capture the particle shape characteristics ${ }^{19}$. Then an image processing software Image-Pro Plus $6.0^{51}$ is used to convert the real image to binary image to obtain shape indices. The experiment procedure is shown as Fig. 14.

Gradation curve model. The form of continuous gradation equation is adopted as Eq. (2). To establish the relationship between gradation equation and the particle shape effect, the overall regularity $(O R)$ is introduced to modify the parameter $\left(a^{\text {sieve }}\right)$ and the particle size ( $\left.D^{\text {sieve }}\right)$. The relationship between the parameter $a^{\text {sieve }} / a^{\text {Fmin }}$ in Eq. (2) and the overall regularity $(O R)$ is found to be linear as shown in Fig. 6. Additionally, an asymptotic relationship between $D^{\mathrm{Fmin}} / D^{\text {sieve }}$ and the overall regularity $(O R)$ is proposed as Eq. (5). Finally, the continuous gradation equation considering particle shape effect can be obtained as Eq. (6). 


\section{Data availability}

418 The data that support the findings of this study are not publicly available due to privacy or ethical restrictions.

\section{Reference}

1. Kuo CY, Rollings RS, Lynch LN. Morphological Study of Coarse Aggregates Using Image Analysis. Journal of Materials in Civil Engineering. 10(3), 135-142 (1998).

2. Pereira CG, Castro-Gomes J, Oliveira L. Influence of natural coarse aggregate size, mineralogy and water content on the permeability of structural concrete. Construction \& Building Materials. 23(2), 602-608 (2009).

3. Dong Z, Huang X, Zhao Y. Investigation of the shape, size, angularity and surface texture properties of coarse aggregates. Construction and Building Materials. 34, 330-336 (2012).

4. Boergesson L, Johannesson LE, Gunnarsson D. Influence of soil structure heterogeneities on the behaviour of backfill materials based on mixtures of bentonite and crushed rock. Applied Clay Science. 23(1/4), 121-131 (2003).

5. Zheng J, Zhu Y, Zhao Z. Utilization of limestone powder and water-reducing admixture in cemented paste backfill of coarse copper mine tailings. Construction \& Building Materials. 124(OCT.15), 31-36 (2016).

6. Li M, Zhang J, Huang Y, et al. Effects of particle size of crushed gangue backfill materials on surface subsidence and its application under buildings. Environmental Earth Sciences. 76(17), 603 (2017).

7. Li M, Li A, Zhang J, et al. Effects of particle sizes on compressive deformation and particle breakage of gangue used for coal mine goaf backfill. Powder Technology. 360, 493-502 (2020).

8. Ashok, Kumar, Gupta. Effects of particle size and confining pressure on breakage factor of rockfill materials using medium triaxial test. Journal of Rock Mechanics and Geotechnical Engineering. 3, 378-388 (2016).

9. Yunjia Wang, Zhihong Zhao, Erxiang Song. Discrete element modeling of the effect of particle shape on creep behavior of rockfills. International journal of geological and environmental engineering. 11(9), 843-847 (2017).

10. Yunjia Wang, Erxiang Song, Zhihong Zhao. Particle mechanics modeling of the effect of aggregate shape on creep of durable rockfills. Computers \& Geotechnics. 98(JUN.), 114-131 (2018).

11. British Standards Institute. Tests for geometrical properties of aggregates. Part 1: Determination of particle size distribution-Sieving method. BS EN 933-1, London (1997).

12. Allen T. Particle size measurement. Vol.1: Powder sampling and particle size measurement, 5th Ed. Chapman \& Hall, London (1997)

13. Rodriguez JM, Edeskar T, Knutsson S. Particle shape quantities and measurement techniques: a review. Electron J Geotech Eng. 18, 169-198 (2013).

14. Cavarretta I. The influence of particle characteristics on the engineering behavior of granular materials (Ph. D. thesis). Imperial College London (2009).

15. Lee, Hyoung, Yoon et al. Particle shape effect on thermal conductivity and shear wave velocity in sands. Acta Geotechnica: An International journal for Geoengineering. 12, 615-625 (2017). 
16. Wadell H.A. Volume, shape and roundness of rock particles. J. Geol. 40(5), 433-451 (1932).

17. Krumbein WC, Sloss LL. Stratigraphy and Sedimentation, 2nded. Freeman, SanFrancisco (1963).

18. Cho G, Dodds J, Santamarina JC. Particle shape effects on pack in gdensity, stiffness and strength: natural and crushed sands. J. Geotech. Geoenviron. Eng. ASCE. 132, 591-602 (2006).

19. Berrezueta E, Cuervas-Mons J, N Rodríguez-Rey, et al. Representativity of 2D Shape Parameters for Mineral Particles in Quantitative Petrography. Minerals. 9(12), 178 (2019).

20. Liu X, Zou D, Liu J, et al. A gradation-dependent particle shape factor for characterizing smallstrain shear modulus of sand-gravel mixtures. Transportation Geotechnics. 28, 100548 (2021).

21. Altuhafi F, O'Sullivan C, Cavarretta I. Analysis of an Image-Based Method to Quantify the Size and Shape of Sand Particles. Journal of Geotechnical \& Geoenvironmental Engineering. 139(8), 1290-1307 (2013).

22. Altuhafi FN, et al. Effect of Particle Shape on the Mechanical Behavior of Natural Sands. Journal of Geotechnical \& Geoenvironmental Engineering. 142(12), 04016071 (2016).

23. Yang J, Wei L M. Collapse of loose sand with the addition of fines: the role of particle shape. Géotechnique. 62(12), 1111-1125 (2012).

24. Ohm HS, Sahadewa A, Hryciw RD, et al. Sustainable Soil Particle Size Characterization Through Image Analysis. Geotechnical \& Geological Engineering. 31(6), 1647-1652 (2013).

25. Zheng Junxing and Hryciw. Traditional soil particle sphericity, roundness and surface roughness by computational geometry. Geotechnique. 65(5), 494-506 (2015).

26. Zheng Junxing and Hryciw. Roundness and Sphericity of Soil Particles in Assemblies by Computational Geometry. Journal of Computing in Civil Engineering. 30(6) (2016).

27. Yang J, Luo X D. Exploring the relationship between critical state and particle shape for granular materials. Journal of the Mechanics \& Physics of Solids. 84(NOV.): JMPSD1500117 (2015).

28. Yang Xiao, Leihang Long, et al. Effect of Particle Shape on Stress-Dilatancy Responses of Medium-Dense Sands. Journal of Geotechnical and Geoenvironmental Engineering. 145(2), (2019).

29. Arda C, Cinicioglu O. Influence of grain shape on stress-dilatancy parameters. Granular Matter. 23(2), 22 (2021).

30. Buckland H M, Saxby J, Roche M, et al. Measuring the size of non-spherical particles and the implications for grain size analysis in volcanology. Journal of Volcanology and Geothermal Research. 45(69), 351346384 (2021).

31. Sharma A, Leib-Day A R, Thakur M M, et al. Effect of Particle Morphology on Stiffness, Strength and Volumetric Behavior of Rounded and Angular Natural Sand. Materials. 14(11), 3023 (2021).

32. Maroof M A, Mahboubi A, Vincens E, et al. Effects of particle morphology on the minimum and maximum void ratios of granular materials. Granular Matter. 24(1), 41 (2022).

33. Fuller WB, Thompson SE. The laws of proportioning concrete. Transactions of the American Society of Civil Engineers. 57(2), 67-143 (1906).

34. Talbot AN, Richart FE. The strength of concrete-its relation to the cement, aggregates and water. Illinois Univ Eng Exp Sta Bulletin. 137, 1-118 (1923). 
35. Zhu Jungao, Guo Wanli, Wang Yuanlong, Wen Yanfeng. Equation for soil gradation curve and its applicability. Chinese Journal of Geotechnical Engineering. 37(10), 1931-1936 (2015).

36. Guo Wanli, Zhu Jungao, Yu Ting, Jin Wei. Application of gradation equation for coarse-grained soil. Rock and Soil Mechanics. Journal of Central South University. 39(10), 3661-3667 (2018).

37. EL Wu, JG Zhu, G Chen, et al., 2020. Gradation equation of coarse-grained soil and its applicability. Journal of Central South University. 27(3), 911-919.

38. Zhu Sheng, Deng Shide, Ning Zhiyuan, Wang Jing. Gradation design method for rockfill materials based on fractal theory. Chinese Journal of Geotechnical Engineering. 39(6), 11511155 (2017).

39. Sun Z, Wang C, Hao X, et al. Quantitative evaluation for shape characteristics of aggregate particles based on 3D point cloud data. Construction and Building Materials. 263, 120156 (2020).

40. Xiao Jiangzhang, Cai Hong, Sun Ping, et al. Equation expression of particle size distribution curve with poor gradation. Water Resources and Hydropower Engineering. 51(S2), 416-421, (2020).

41. Guo Wanli, Zhu Jungao, Wen yanfeng. Unified description for four gradation scale methods for coarse aggregate. Chinese Journal of Geotechnical Engineering. 38(8), 1473-1480 (2016).

42. Sympatec. Windox-operating Instructions Release 5.4.1.0, Sypatec GmbH. ClausthalZellerfeld, Germany (2008).

43. Wang Qiyun, Xiang Yulong, Zhang Bingqiang, et al. Study on establishing and application of gradation equation for coarse-grained soil. Science Technology and Engineering. 20(31), 12968-12973 (2020).

44. Ren Yubin, Wang Yin, Yang Qing, 2018. Effect of particle size distribution and shape on permeability of calcareous sand. Rock and Soil Mechanics. 39(2), 491-497.

45. Peng Jiayi. Study on the effect of particle shape on the permeability of coarse-grained soil. Changjiang River Scientific Research Institute (2017).

46. Houzhen Wei, Tao Zhao, Qingshan Meng, et al. Quantifying the Morphology of Calcareous sands by dynamic image analysis. Int. J. Geomech. 20(4), 04020020 (2020).

47. Zhao B, Wang J. 3D quantitative shape analysis on form, roundness, and compactness with 4CT. Powder Technol. 291, 262-275 (2016).

48. Nie Z, Wang X, Liang Z, et al. Quantitative analysis of the three-dimensional roundness of granular particles. Powder Technology. 336, S0032591018304601 (2018).

49. Sun Q, Zheng J, Coop M R, et al. Minimum image quality for reliable optical characterizations of soil particle shapes. Computers and Geotechnics. 114(Oct.),103110.1-103110.6 (2019).

50. Weichen Sun, Kai Wu, Haibo Huang. A graded granular material generation algorithm based on particle number probability distribution by DEM. Physica A: Statistical Mechanics and its Applications. 573(6), 125919 (2021).

51. Image-pro plus. Version number, 6.0. May. Media Cybernetics. Maryland, America (2019). URL: www.mediacy.com/imageproplus 
543 This work is supported by the National Natural Science Foundation of China (Grant

544 No. 51678570 and 51978665$)$.

\section{Author contributions}

547 Zexiong Shi and Liang Deng conducted sieve experiments, divided eight kinds of 548 crushed stone into unified gradation, photographed the photos of Fig. 13 and Fig. 14a 549 and sampled all the crushed stone sieved. Xin Ding processed all the crushed stone data 550 through image and data processing software including Figs. 14b, c and d, and wrote 551 part of the paper. By analyzing and processing the data, Li Pang introduced the 552 gradation curve formula model to obtain the gradation curve model considering the 553 influence of particle shape, and wrote the rest of the paper. Chong Jiang summarized 554 the whole paper, gave guiding opinions, and corrected the mistakes in the process of 555 writing the paper.

558 The authors declare no competing interests. 